\title{
Comparative analysis of radical prostatectomy techniques using perineal or suprapubic approach in the treatment of localized prostate cancer
}

\author{
Análise comparativa das técnicas de prostatectomia radical perineal e suprapúbica na \\ abordagem do câncer de próstata localizado
}

Gelbert Luiz Chamon do Carmo Amorim¹, Geraldo Magela Gomes da Cruz², Denny Fabrício Magalhães Veloso ${ }^{3}$, José David Kartabil ${ }^{4}$, José Carlos Vieira ${ }^{5}$, Paulo Roberto Alves ${ }^{6}$

\begin{abstract}
Objective: To compare the results of radical prostatectomy by perineal and suprapubic approaches as to operative time, procedure costs, and surgical site complications. Methods: The medical records of localized prostate cancer patients (PSA $\leq 10 \mathrm{ng} / \mathrm{ml}$ and Gleason score $\leq 6$ ) were analyzed. Fifty-five patients were submitted to radical prostatectomy by perineal approach and 54 via suprapubic approach. Results: There were statistical differences between groups as to operative time $(p<0.05)$; for perineal approach it was in average 114 minutes $(S D \pm 0.03$ ) and for suprapubic approach, an average of 167 minutes $(S D \pm 0.041)$. Prostatectomy via perineal approach resulted in 11 cases of surgical complications, and suprapubic approach, 3 cases. Conclusions: Radical prostatectomy via perineal approach took less time at a lower cost as compared to the suprapubic approach. However, there were more complications in patients submitted to perineal approach, mainly rectal lesions.
\end{abstract}

Keywords: Prostatectomy/methods; Prostatectomy/economics; Prostatectomy/adverse effects; Prostatic neoplasms

\section{RESUMO}

Objetivo: Comparar os resultados da prostatectomia radical por acesso perineal e por via suprapúbica quanto ao tempo operatório, custo de realização do procedimento e complicações do sítio cirúrgico. Métodos: Foram analisados os prontuários de pacientes com câncer de próstata localizados (PSA $\leq 10 \mathrm{ng} / \mathrm{ml}$ e escore de Gleason $\leq 6$ ) sendo 55 submetidos à técnica de prostatectomia perineal e 54 à técnica suprapúbica (PRSP). Resultados: Houve diferença estatística entre os grupos quanto ao tempo operatório $(p<0,05)$. 0 tempo médio para a realização de todo 0 ato operatório por acesso perineal foi 114 minutos em média $(D P \pm 0,03$ ) e de 167 minutos em média $(\mathrm{DP} \pm 0,041)$ quando empregado 0 acesso suprapúbico. 0 índice de complicações cirúrgicas decorrentes das prostatectomias realizadas foi de 11 casos na prostatectomia radical perineal e de 3 casos submetidos à técnica suprapúbica. Conclusões: A prostatectomia radical pelo acesso perineal foi realizada em menor tempo com menor custo do procedimento quando comparada à operação realizada pelo acesso suprapúbico. Entretanto, relacionou-se a maior incidência de complicações em comparação ao acesso suprapúbico, principalmente com relação à lesão retal.

Descritores: Prostatectomia/métodos; Prostatectomia/economia; Prostatectomia/efeitos adversos; Neoplasias da próstata

\section{INTRODUCTION}

Prostate neoplasm is the second most common tumor in men. Until the 1980s, most patients were diagnosed when the disease was already in an advanced stage, but this scenario changed as diagnostic tests improved, particularly with the advent of the prostate-specific antigen (PSA). Radical treatment aimed to cure organrestricted neoplasm can be performed by radiation therapy or radical prostatectomy, and the latter presents the best results.

\footnotetext{
Study carried out at Santa Casa de Belo Horizonte, Belo Horizonte (MG), Brazil

${ }^{1}$ Master's degree; MD at Santa Casa de Belo Horizonte, Belo Horizonte (MG), Brazil.

2 PhD; MD at Santa Casa de Belo Horizonte, Belo Horizonte (MG), Brazil.

${ }^{3}$ Master's degree; MD at Santa Casa de Belo Horizonte, Belo Horizonte (MG), Brazil.

${ }^{4}$ Urologist at Santa Casa de Belo Horizonte, Belo Horizonte (MG), Brazil.

${ }^{5}$ Urologist at Santa Casa de Belo Horizonte, Belo Horizonte (MG), Brazil.

${ }^{6}$ Urologist at Santa Casa de Belo Horizonte, Belo Horizonte (MG), Brazil.

Corresponding author: Gelbert Luiz Chamon do Carmo Amorim - Rua Candido Gonçalves Dos Reis, 601 - São Cristóvão - CEP 35700271 - Sete Lagoas (MG), Brazil - Tel.: 31 3774-7500 - e-mail: gelbertchamon@hotmail.com

Received on Jan 12, 2010 - Accepted on May 14, 2010

The authors declare there is no conflict of interest
} 
Treatment results are related to neoplasm staging. The best are obtained when the neoplasm is confined to the organ. Pelvic lymphadenectomy of the obturator basin may also be employed for staging during surgery. However, several authors reported that lymphadenectomy is not necessary in patients with minimum risk of pelvic lymph node metastasis ${ }^{(1-3)}$, such as those which Gleason score $<7$ at biopsy and PSA $\leq$ $10 \mathrm{ng} / \mathrm{ml}$.

The predominant Gleason score, when staging prostate cancer in a homogenous group and with probable localized disease (PSA $\leq 10 \mathrm{ng} / \mathrm{ml}$ ), is predominantly 3.3, as observed by Lance et al. ${ }^{(4)}$ and Doblet et al. ${ }^{(5)}$.

As to operative time, perineal approach is briefer due to anatomic reasons, since it provides direct access to the prostate. Salomon et al. ${ }^{(6)}$ reported an average duration of 178 minutes by perineal approach and 197 minutes by suprapubic approach. $\operatorname{Resnik}^{(7)}$ also obtained similar findings. Such studies suggest that access to the prostate is faster via the perineum, with less surgical layers.

In addition to neoplasm control results, treatment costs must be considered. During the last decades, surgical treatment has considerably changed as to organ access and directly related costs. Videolaparoscopy, particularly with the use of robotics, is still unavailable for urologic procedures in many parts of the world mainly due to financial reasons. Perineal approach was firstly used in the beginning of urology for the removal of bladder calculi with patients placed in lithotomy. The suprapubic approach is currently more often employed in Brazil, and was developed as knowledge about pelvic anatomy advanced.

Gillitzer and Thuroff ${ }^{(8)}$ evaluated open prostatectomy costs and concluded that perineal approach is approximately $42 \%$ less expensive than the suprapubic approach. Harris ${ }^{(9)}$, in 2003 , pointed out that perineal approach is a simple and minimally invasive surgical procedure, contributing to faster recovery of patients and lower financial costs.

Rectal lesion is described in all studies on the use of perineal approach in prostatectomy, with incidences of $4.9 \%$ in Lance et al. ${ }^{(4)}$ and of $1 \%$ in Hiraoka et al. ${ }^{(10)}$. Gillitzer et al. ${ }^{(8)}$ reported up to $3 \%$ rectal lesion when prostatectomy was performed by an experienced surgeon and up to $11 \%$ during the learning curve. All studies mentioned that rectal lesion is easy to repair, provided it is diagnosed perioperatively. A two-layer suture must be used. Rectal lesion may evolve to fistula in up to $3.6 \%$ of cases, requiring colostomy to deviate intestinal transit. Sullivan et al. ${ }^{(11)}$ reported $5 \%$ of rectal lesions using the perineal technique. Doblet et al. ${ }^{(5)}$, studying 24 patients operated by perineal technique, described 3 cases of rectal lesion, and only one case in a group of 16 patients operated by the suprapubic technique. Other studies showed higher rates of rectal lesion in perineal prostatectomy, and mentioned it was the most serious complication ${ }^{(12-14)}$.

The occurrence of urinary fistula has been reported in all studies and for both techniques. Gillitzer and Thuroff ${ }^{(8)}$ described $3.5 \%$ of primary fistulas in a series employing both techniques, which is consistent with the findings of Sullivan et al. ${ }^{(11)}$. Treatment of the fistula is initially based on the use of an indwelling bladder catheter.

Urinary retention was also described in studies on both surgical techniques. It is probably caused by the type of anastomosis and diameter of the bladder neck when reconstructing the neck. Harris ${ }^{(9)}$ reported urinary retention in $2 \%$ of patients submitted to both surgical techniques. Sullivan et al. ${ }^{(1)}$ registered $19 \%$ ofurinary retention and stenosis of the urethrovesical anastomosis in a similar study.

Both Sullivan et al. ${ }^{(11)}$ and Gillitzer et al. ${ }^{(8)}$ found a $5 \%$ incidence of surgical wound infection due to hematoma or other reasons, in both techniques. However, Lance et al. ${ }^{(4)}$ verified higher incidence of infection as to perineal approach, amounting to $2 \%$ as compared to suprapubic access.

\section{OBJECTIVE}

The objective of this study was to compare the results of radical prostatectomy radical via perineal or suprapubic approach as to operative time, procedure costs, and surgical site complications.

\section{METHODS}

The study was approved by the Research Ethics Committee of the Institution, and all patients enrolled signed an informed consent form. Patients' treatment and follow-up were not influenced by their participation in the study.

This was a retrospective study of records of patients operated by the same medical team at a public and teaching hospital that is a reference for oncological treatment in the State of Minas Gerais. In total, 400 patients were operated between January 2000 and September 2005. Patients with localized prostate neoplasm confined to the organ, as detected by digital rectal examination, prostatespecific antigen (PSA) of up to $10 \mathrm{ng} / \mathrm{dl}$, and Gleason score up to 6. Patients with contraindications to the procedure, such as life expectancy lower than 10 years and surgical risk higher than II, according to the criteria of the American Society of Anesthesiologists, were excluded. In total, 291 records were analyzed according to the described criteria. 
Two groups of patients were compared: those operated via perineal approach and those operated via suprapubic technique. The following variables were analyzed: operating time, incidence of surgical complications, and cost of performing prostatectomy. After reviewing the records, 109 patients - from whom all the data to be analyzed were available - were studied. The complications considered in the study were those directly related to the surgical bed, such as rectal lesion, urinary fistula, postoperative bleeding, surgical site infection, etc. Pulmonary, cardiovascular, and any other complications generically related to a surgery other than prostatectomy, were excluded.

Spinal block by spinal anesthesia and secondarily by epidural anesthesia are preferable in prostatectomy, independently if performed via perineal or suprapubic approaches. General anesthesia may be used if there is any contraindication to spinal block.

\section{Perineal group}

Radical perineal prostatectomy is performed with the patient in high lithotomy position. Skin incision is semicircular, anterior to the anus, with limbs placed 1.5$\mathrm{cm}$ apart from the ischial tuberosities, on each side. The central tendineous point of the perineum is dissected until the bulbar urethra is identified and transected to allow prostrate retraction. The prostate is dissected from its apex towards the bladder neck, and vessels are ligated and transected. The vas deferens and the seminal vesicles are then dissected and have their vessels ligated and transected. The urethra is isolated and transected, as well as the bladder neck for prostate and seminal vesicle monobloc ressection. Vesicourethral anastomosis is performed under direct view by continuous suture using PDS 3-0 thread. Finally, the indwelling vesical catheter is introduced, hemostasia is checked, Penrose drainage is performed through the incision and the deep layers are sutured using catgut 3-0 and the skin using nylon 3-0.

\section{Suprapubic group}

Suprapubic prostatectomy is carried out with the patient in supine position, with discrete hyperextension of the table, by midline incision from the umbilicus to the root of the penis. Layers are dissected in the preperitoneal retropubic space to expose the anterior face of the prostate and the vesicoprostatic junction. Then, the lateral faces and apex of the prostate are dissected, and posteriorly, the endopelvic fascia is opened on each side, and the dorsal vein complex of the penis is ligated with vycril 2-0. The urethra is exposed, transected, and repaired with 5 separate stitches using vycril 3-0 for subsequent anastomosis. The posterior face of the prostate is dissected, and prostatic vessels are ligated and transected. The procedure continues with the release of the prostate up to the bladder neck and exposure of Denonvillier fascia, which is opened for dissection of seminal vesicles and vas deferens. Prostatic base is transected at the bladder neck, and the piece is resected in monobloc. Hemostasia is checked and an indwelling catheter is introduced. Finally, the vesicourethral anastomosis is performed using previously separated threads, in a total of 6 to 8 Vycril 3-0 threads. Knots are brought near by palpation, and the approximation of the bladder to the urethra is maintained by traction of the indwelling vesical catheter. Lastly, the surgical bed is drained with a Penrose drain and the layers are sutured with Vycril 1 and Nylon 3-0.

The financial cost of each procedure was calculated based on the data recorded in the operating room. Any material used during the surgery was considered. Aiming to establish a standard independent from Brazilian indexation and to correct the costs to current values, the hospital coefficient (HC) was used, which is commonly employed in health insurance compensation and changes along time. Surgery expenses were converted into $\mathrm{HC}$ according to the quotation at the time the procedure was performed. $\mathrm{HC}$ values were converted into Brazilian currency, and one $\mathrm{HC}$ unit today is equivalent to US\$ 0.16 approximately.

For statistical purposes, the descriptive methods of mean and mean standard error were used. Results were compared by analysis of variances. Categorical variables were analyzed by the $\chi^{2}$ test. The differences were considered significant at $\mathrm{p}<0.05$.

\section{RESULTS}

A total of 55 patients were studied in the Perineal Group and 54 in the Suprapubic Group.

Data analysis showed that mean age was not statistically different between the groups, being 64.4 in the perineal radical prostatectomy group (PRP) and 62.9 in the suprapubic radical prostatectomy group (SPRP).

In the Perineal Group, the mean PSA was $6.6 \mathrm{ng} / \mathrm{dl}$ and, in the Suprapubic Group, $6.75 \mathrm{ng} / \mathrm{dl}$. There was no statistical difference in PSA values between the groups that were studied. No patient presented PSA higher than $10 \mathrm{ng} / \mathrm{dl}$.

In both groups, the most frequent Gleason score was $6(3+3)$, occurring in $80 \%$ in the Perineal Group and in $88 \%$ in the Suprapubic Group. Table 1 shows patient distribution according to Gleason scores. There was no significant difference between the groups as to Gleason score. 
Table 1. Distribution of Gleason score in the groups of patients submitted to radical prostatectomy by perineal or suprapubic approach

\begin{tabular}{lcccc}
\hline \multirow{2}{*}{ Gleason score } & \multicolumn{4}{c}{ Groups } \\
\cline { 2 - 5 } & \multicolumn{2}{c}{ Perineal } & \multicolumn{2}{c}{ Suprapubic } \\
\cline { 2 - 5 } & $\mathbf{n}$ & $\%$ & $\mathbf{n}$ & $\%$ \\
\hline 3 & 4 & 7.5 & 2 & 3.5 \\
4 & 2 & 3.5 & 3 & 5.5 \\
5 & 5 & 9 & 1 & 2 \\
6 & 44 & 80 & 48 & 89 \\
\hline Total & 55 & 100 & 54 & 100 \\
\hline
\end{tabular}

n: number of patients.

Operative time was statistically different between groups $(\mathrm{p}<0.05)$. Mean time for the entire surgery when perineal approach was used was 114 minutes (SD: 0.03 ) and 167 minutes (SD: 0.041) when suprapubic technique was employed.

The surgery cost in the Perineal Group (mean $3,430.60 \mathrm{HC}$, corresponding to $\mathrm{R} \$ 1,029.18=\mathrm{US} \$$ 571.76) was significantly lower $(\mathrm{p}<0.05)$ as compared to that of the Suprapubic Group (mean 5,569.31 HC, corresponding to $\mathrm{R} \$ 1,569.31=$ US\$ 871.83).

Blood transfusion rate was statistically similar between techniques, with $12.7 \%$ in PRP and $11.1 \%$ in SPRP.

Patients used indwelling vesical catheters for similar periods in both groups, with an average of 11.8 days in PRP and 13.7 days in SPRP, without statistical difference.

The occurrence of urinary fistula was statistically higher $(\mathrm{p}<0.05)$ in PRP, with 4 cases $(3.7 \%)$, as compared to SPRP, with 1 case $(1.8 \%)$; all cases were satisfactorily treated with indwelling vesical catheters.

The surgical complication rates derived from prostatectomy were 11 cases in PRP and three cases in SPRP. Table 2 presents the complication according to the group evaluated.

Table 2. Operative complications developed in the surgical site in patients submitted to radical perineal or suprapubic prostatectomy to treat prostate cancer

\begin{tabular}{lcccc}
\hline \multirow{2}{*}{ Complications } & \multicolumn{4}{c}{ Group } \\
\cline { 2 - 5 } & \multicolumn{2}{c}{ Perineal } & \multicolumn{2}{c}{ Suprapubic } \\
\cline { 2 - 5 } & $\mathbf{n}$ & $\%$ & $\mathbf{n}$ & $\%$ \\
\hline Urinary fistula & 3 & 5.5 & 1 & 1.8 \\
Penile hematoma & 0 & - & 1 & 1.8 \\
Parietal hematoma & 1 & 1.8 & 1 & 1.8 \\
Surgical site infection & 1 & 1.8 & 0 & - \\
Rectal lesion & $6^{*}$ & 10.9 & 0 & - \\
\hline Total & $11^{*}$ & 20 & 3 & 5.4 \\
${ }^{*} \mathrm{p}<0.05$ & & & &
\end{tabular}

\section{DISCUSSION}

Suprapubic approach is currently the preferred method used by most Brazilian urologists for radical prostatectomy. Perineal prostatectomy learning curve is fast $^{(15)}$; however, this access does not allow performing pelvic lymphadenectomy. On the other hand, lymphadenectomy may not be required, depending on disease staging ${ }^{(16-20)}$.

The present study yielded similar results as those reported in literature, such as the prevalent Gleason score $3.3^{(4,5)}$. This was mainly due to the fact that homogeneous groups were obtained, consisting of patients with potentially localized neoplams ${ }^{(17)}$. PSA and patient's age data were also consistent with literature findings.

Operative time presented statistical differences, with $\mathrm{PRP}$ being briefer as compared to $\mathrm{SPRP}^{(6)}$. This finding is important particularly when the surgery cost is evaluated, since a technique with shorter operative time results in lower operating theater costs. PRP was also cheaper for enabling direct access to the prostate, with a lower number of layers that require reconstruction. PRP cost in the present study was $40 \%$ lower as compared to SPRP.

Regarding the occurrence of urinary fistula in this series, PRP rate was statistically higher than SPRP; all fistulas were successfully treated with indwelling vesical catheters.

\section{CONCLUSIONS}

Perineal approach in radical prostatectomy was performed in a shorter operative time and at a lower cost. However, there was a higher incidence of surgical site complications as compared to suprapubic technique, particularly rectal lesions and urinary fistula.

\section{REFERENCES}

1. Partin AW, Kattan MV, Subong E, Walsh PC, Wojno KJ, Oesterling, JE. Combination of prostate-specific antigen, clinical stage, and Gleason score to predict pathological stage of localized prostate cancer. A multi-institutional update. JAMA. 1997;277(18):1445-51.

2. Salomon L, Levrel O, Anastasiadis AG, Saint F, Taille A, Cicco A, et al. Outcome and complications of radical prostatectomy in pacients with PSA $<10 \mathrm{ng} /$ $\mathrm{ml}$ : comparison between the retropubic, perineal and laparoscopic approach. NPG. 2002;5(4):285-90.

3. Ung J0, Richie JP, Chen MH, Renshaw AA, DAmico AV. Evolution of the presentation and pathologic and biochemical outcomes after radical prostatectomy for patients with clinically localized prostate cancer diagnosed during the PSA era. Urology. 2002;60(3):458-63

4. Lance RS, Freidrichs PA, Kane C, Powell CR, Pulos E, Moul JW. A comparison of radical retropubic with perineal prostatectomy for localized prostate cancer within the Uniformed Services Urology Research Group. BJU Int. 2001;87(1):61-5.

5. Doblet JD, Lagrange L, Ciofu C, Thibault P, Gattegno B. Radical prostatectomy: comparison of the perineal and retropubic route (40 patients). Preliminary results. Prog Urol.1994;4(1):33-9.

6. Salomon L, Levrel O, DeLaTaille A, Anastasiadis AG, Saint F, Zaki S, et al. Radical prostatectomy by the retropubic, perineal and laparoscopic approach: 12 years of experience in one center. Eur Urol. 2002;42(2):104-10. 
7. Resnick MI. Radical perineal prostatectomy. BJU Int; 2003;92(6):522-3.

8. Gillitzer R, Thuroff JW. Relatives advantages and disadvantages of radical perineal prostatectomy versus radical retropubic prostatectomy. Criticals Reviews in Oncology/Hematology. 2002;43(2):167-90.

9. Harris MJ. Radical perineal prostatectomy: cost efficient, outcome effective, minimally invasive prostate cancer management. European Urology. 2003;44(3):303-8.

10. Hiraoka Y, Takahashi H, Shimizu Y, Suzuki Y, Iwamoto K, Zuo W. A comparison of radical perineal and radical retropubic prostatectomy. BJU. 2002;90(1):164-70.

11. Sullivan LD, Weir MJ, Kinahan JF, Taylor D. A comparison of the relative merits of radical perineal and radical retropubic prostatectomy. BJU Int. 2000;85(1):95-100.

12. Lassen PM, Kearse WS Jr. Rectal Injuries during radical perineal prostatectomy. Urology. 1995;45(2):266-79.

13. Bishoff JT, Motley G, Optenberg SA, Stein CR, Moon KA, Browning SM. Incidence of fecal and urinary incontinence following radical perineal and retropubic prostatectomy in a national population. J Urol. 1998;160(2):454-8.

14. PriceDT, Vieweg J, RolandF, CoetzeeL, Spalding T, IselinC. Transientlower extremity neuropraxia associated with radical perineal prostatectomy: a complication of the exaggerated lithotomy position. J Urol. 1998;160(4):1376-8.
15. Mokulis J, Thompson I. Radical prostatectomy: is the perineal approach more difficult to learn? J Urol. 1997;157(1):230-2.

16. Bluestein DL, Bostwick DG, Bergstrahl EJ, Oesterling JE. Eliminating the need for bilateral pelvic lymphadenectomy in select patients with prostate cancer. J Urol. 1994;151(5):1315-20.

17. D'Amico AV, Whittington R, Malkowicz SB, Wu YH, Chen M, Art M et al. Combination of the preoperative psa level, biopsy gleason score, percentage of positive biopsies, and MRI T stage to predict early psa failure in mem with clinically localized prostate cancer. Urology. 2000;55(4):572-7.

18. Parra RO, Isorna S, Perez MG, Cummings JM, Boullier JA. Radical perineal prostatectomy without pelvic lymphadenectomy: selection criteria and early results. J Urol. 1996;155(2):612-5.

19. Fergany A, Kupelian PA, Levin HS, Zippe CD, Reddy C, Klein EA. No difference in biochemical failure rates with or without pelvic lymph node dissection during radical prostatectomy in low risk patients. Urology. 2000;56(1):92-5.

20. Salomon L, Hoznek A, Lefrere MA, Belda J, Bellot DK, Chopin CC. Nondissection of pelvic lymph nodes does not influence the results of perineal radical prostatectomy in selected patients. Eur Urol. 2000;37(3):297-300. 